\section{New Insight on the Role of Electrolyte Additives in Rechargeable Lithium lon Batteries}

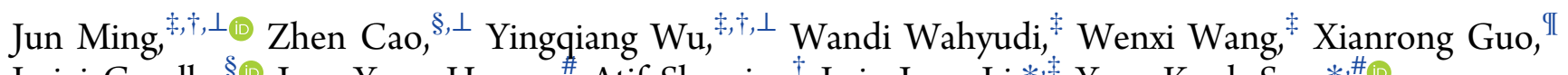
Luigi Cavallo, ${ }^{\S \odot}$ Jang-Yeon Hwang, Atif Shamim, ${ }^{\dagger}$ Lain-Jong Li, ${ }^{*},+$ Yang-Kook Sun, ${ }^{*}, \#(0)$ and Husam N. Alshareef*, $* 0$

${ }^{\ddagger}$ Materials Science and Engineering, Physical Science and Engineering Division, King Abdullah University of Science and Technology (KAUST), Thuwal 23955-6900, Saudi Arabia

'State Key Laboratory of Rare Earth Resource Utilization, Changchun Institute of Applied Chemistry, Chinese Academy of Sciences, Changchun 130022, People's Republic of China

${ }^{\S}$ Physical Science and Engineering Division, King Abdullah University of Science and Technology (KAUST), KAUST Catalysis Center (KCC), Thuwal 23955-6900, Saudi Arabia

${ }^{\text {II }}$ Core Laboratories, King Abdullah University of Science and Technology (KAUST), Thuwal 23955-6900, Saudi Arabia

\#Department of Energy Engineering, Hanyang University, Seoul 133-791, Republic of Korea

Supporting Information

ABSTRACT: Solid electrolyte interphase (SEI)-forming agents such as vinylene carbonate, sulfone, and cyclic sulfate are commonly believed to be film-forming additives in lithium-ion batteries that help to enhance graphite anode stability. However, we find that the film-forming effect and the resultant SEI may not be the only reasons for the enhanced graphite stability. This is because the as-formed SEI cannot inhibit $\mathrm{Li}^{+}$-solvent cointercalation once the additive is removed from the electrolyte. Instead, we show that the $\mathrm{Li}^{+}$solvation structure, which is modified by these additives, plays a critical role in achieving reversible $\mathrm{Li}^{+}$ (de)intercalation within graphite. This discovery is confirmed in

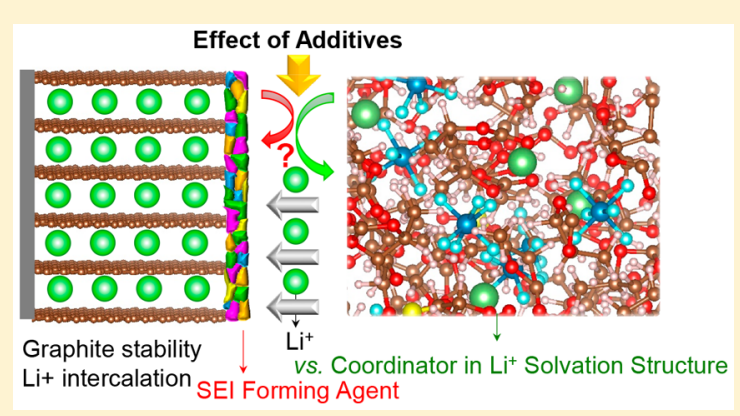
both carbonate and ether-based electrolytes. We show that the problem of graphite exfoliation caused by $\mathrm{Li}^{+}-$solvent cointercalation can be mitigated by adding ethene sulfate to tune the $\mathrm{Li}^{+}$coordination structure. This work brings new insight into the role of additives in electrolytes, expanding the prevailing thinking over the past 2 decades. In addition, this finding can guide the design of more versatile electrolytes for advanced rechargeable metal-ion batteries.

S olid electrolyte interphase (SEI)-forming agents play a significant role in rechargeable battery systems because they can enhance the performance of electrodes and electrolytes. $^{1-9}$ One of the most successful examples is the improved graphite stability in carbonate-based electrolytes, ${ }^{10-16}$ particularly in propylene carbonate (PC) solvent, ${ }^{17-29}$ allowing their wider application (e.g., low or high temperature, high voltage) in lithium-ion batteries. To date, this enhanced graphite stability has been commonly ascribed to the film-forming effect, where the SEI can be modified by the reduction of additives at a higher potential than the solvent. The more robust SEI can passivate the electrode and reduce the reduction of electrolyte components on the electrode surface for most carbonate (ethylene carbonate, EC)-based (PC-free) electrolytes. In addition, the SEI may also suppress the structural damage of graphite (its well-known exfoliation issue) in PC-based electrolytes. ${ }^{17-32}$ However, herein we show that the film-forming effect of additives cannot alone account for the graphite stability. This is because the SEI-protected graphite is found to be unstable once the additives are removed from the battery. We reveal that the real role of additives is changing the lithium $\left(\mathrm{Li}^{+}\right)$solvation structure in the electrolyte; although the additive can affect the chemical composition of SEI, as-formed SEI is incapable of stabilizing the graphite. We show that the additive plays a coordinator role in the electrolyte, which changes the $\mathrm{Li}^{+}$-solvent interaction. Thus, the additive ultimately determines the behavior of $\mathrm{Li}^{+}$ions or $\mathrm{Li}^{+}$clusters, such as the competitive

Received: July 4, 2019

Accepted: October 8, 2019

Published: October 8, 2019 
a

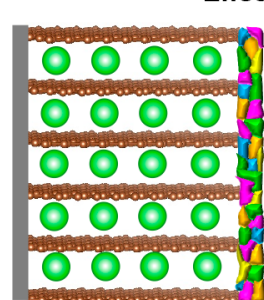

Graphite stability Li+ intercalation
Effect of Additives

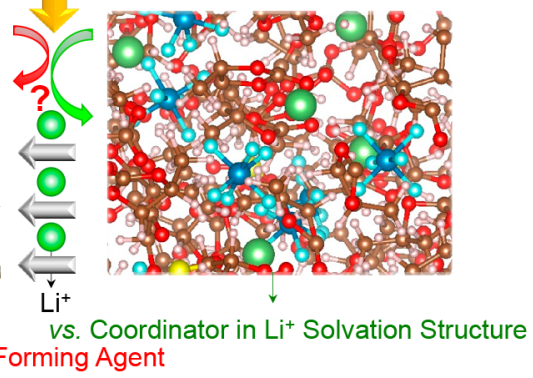

C

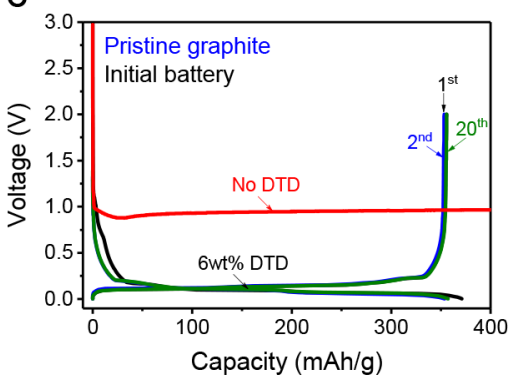

Re-assemble

e

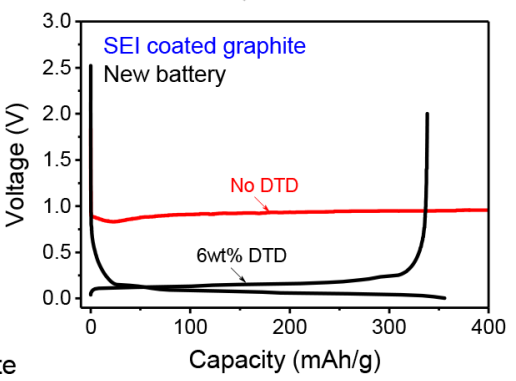

Figure 1. Effect of additives on $\mathrm{Li}^{+}$ion (de)interaction within graphite. (a) Schematic illustration of the controversial role of the additive effect on graphite stability: the commonly believed film-forming additive effect or another effect (e.g., coordinator in $\mathrm{Li}^{+}$solvation structure to change the nature of the electrolyte). (b) Pristine graphite electrode (vs metallic Li) cycles in the electrolyte, where the SEI is formed on the graphite when film-forming additives are used, giving rise to SEI-coated graphite in the initial battery. (c) Typical voltage vs capacity profiles of graphite in the electrolyte of $1.0 \mathrm{M} \mathrm{LiPF}_{6}$ in PC with and without 6 wt \% DTD. (d) SEI-coated graphite electrode disassembled from the initial battery and reassembled (vs metallic lithium) in a new battery. (e) Typical voltage vs capacity profiles of SEI-coated graphite cycled in the electrolyte of $1.0 \mathrm{M} \mathrm{LiPF}_{6}$ in PC with and without 6 wt \% DTD.

(de)intercalation of $\mathrm{Li}^{+}$or co-intercalation of $\mathrm{Li}^{+}-$solvents within graphite. Excellent research about the coordinative role of electrolyte additives has been reported, ${ }^{33-35}$ but this is the first try to discover and emphasize their dominant role in determining the $\mathrm{Li}^{+}$(de)intercalation or $\mathrm{Li}^{+}$-solvent coinsertion behaviors within graphite. This viewpoint is different from the commonly believed film-forming agent effect. Our new discovery is the first that has been proven both in the common carbonate-based electrolytes and in ether-based electrolytes.

Ether-based electrolytes are widely used in current lithiumsulfur $(\mathrm{Li}-\mathrm{S})$ and lithium-oxygen $\left(\mathrm{Li}-\mathrm{O}_{2}\right)$ batteries. $^{36}$ However, there is no literature reporting the use of additives to improve graphite stability and the ability to store lithium successfully in these systems. The storage of lithium within graphite could be an alternative and efficient strategy to address the safety issue of metallic lithium ${ }^{37}$ and mitigate the side-reactions of lithium with oxygen or lithium polysulfide in $\mathrm{Li}-\mathrm{O}_{2}$ and $\mathrm{Li}-\mathrm{S}$ batteries, respectively. ${ }^{38-42}$ Although excellent reports have recently been published on the superhigh concentration strategy to stabilize graphite, ${ }^{43-49}$ the effect that makes the super-high-concentrated electrolyte work could be further explored from a different viewpoint.

In this study, we show that additives with strong coordination ability can make the ether-based electrolyte work as well as the carbonate-based electrolyte without the need to use the superhigh concentration strategy. In addition, we introduce a basic unit of the $\mathrm{Li}^{+}$solvation structure model to show the coordinative behaviors of additives, which would be very useful for understanding the molecular behaviors in the electrolyte. This work not only presents new knowledge on the additive role in electrolytes but can also guide the design of more versatile electrolytes for advanced metal (ion) batteries.

Controversial Role of the Additive Effect. The controversial issue of the electrolyte additive effect on graphite anode stability is presented in Figure 1a; the model of PC-based electrolyte with ethylene sulfate (DTD) additive is studied first in a graphite-based lithium battery (i.e., graphite vs lithium). As can be seen, graphite is stabilized with the capacity at around $353 \mathrm{mAh} \mathrm{g}^{-1}$ in a PC-based electrolyte using around 4-6 wt \% DTD (Figures S1-S4), where an SEI can be formed on the graphite surface (Figure 1b). A typical good (dis)charge curve without continuous electrolyte reduction and/or graphite exfoliation $^{22,50}$ is confirmed (Figure 1c); meanwhile, a long cycle life over hundreds of cycles can be maintained (Figure S1A,B). Then, we disassemble this initial battery after several cycles and take out the SEI-coated graphite, where the SEI-coated graphite is reassembled as an electrode in a new battery, as shown in Figure 1d. We find that the SEI-coated graphite can work well with the capacity at around $353 \mathrm{mAh}$ $\mathrm{g}^{-1}$ continually in the same electrolyte with 6 wt \% DTD but fails immediately in DTD-free electrolyte (Figure 1b,d). The serious electrolyte reduction and graphite exfoliation are both observed at around $0.94 \mathrm{~V}$ in dry and wet SEI-coated graphite (Figures 1e and S1C) in the new battery without DTD additives. This is similar behavior to pristine graphite tested in DTD-free electrolyte or in electrolytes with less than $4 \mathrm{wt} \%$ DTD (Figure S1A). This result demonstrates that the SEI layer cannot stabilize graphite for reversible $\mathrm{Li}^{+}$(de-)intercalation. Note that the SEI-coated graphite in the new battery can continually cycle in the electrolyte with $6 \mathrm{wt} \%$ DTD (Figure S1D). In fact, the first (dis-)charge curve in Figure $1 \mathrm{~b}$ almost overlaps with that of stabilized graphite in the initial battery, 

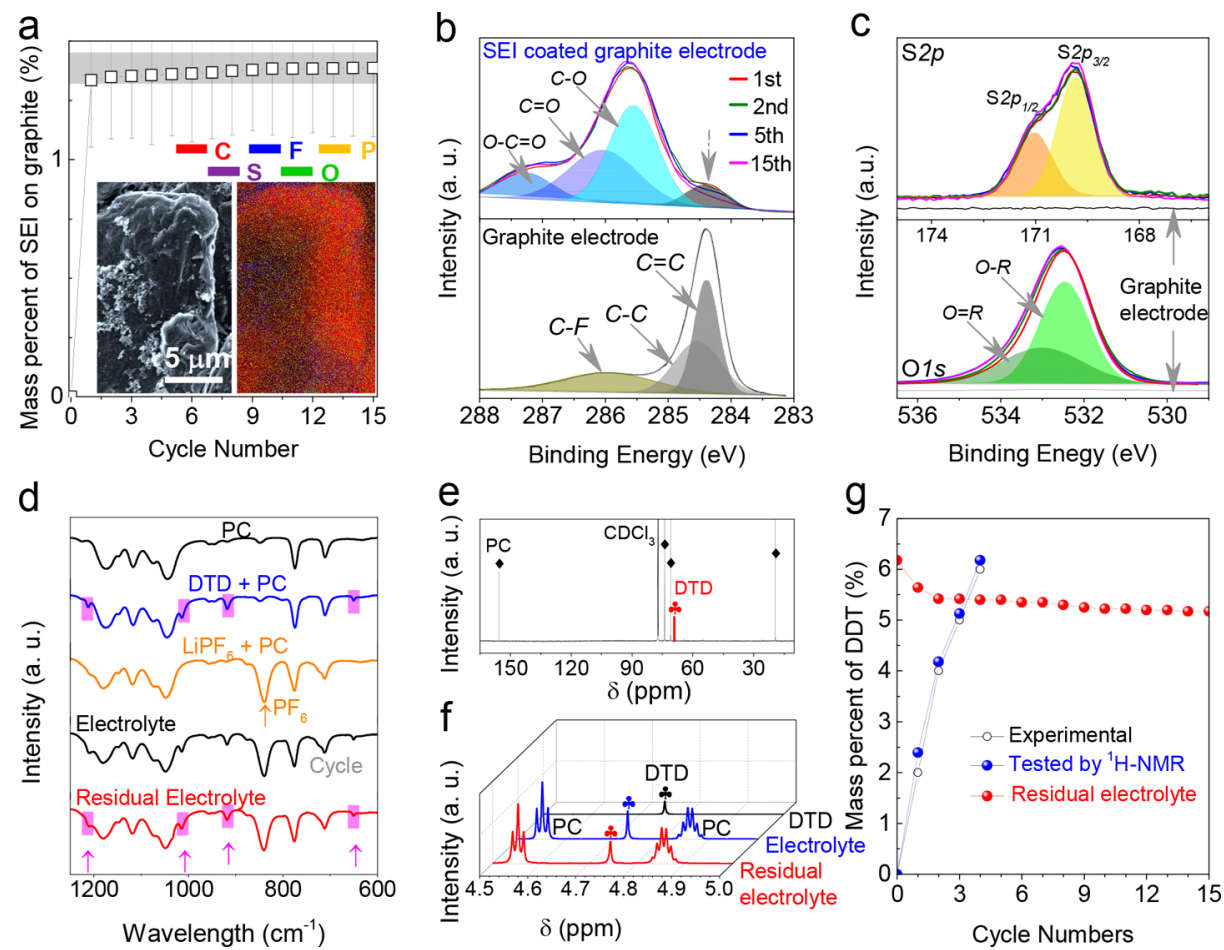

Figure 2. Confirmation of residual additive in electrolyte. (a) Weight variation of SEI on the graphite electrode with cycling in the electrolyte of $1.0 \mathrm{M} \mathrm{LiPF}_{6}, 6$ wt \% DTD in PC. Insets show the SEM image and energy-dispersive X-ray analysis (EDXA) of the SEI-coated graphite electrode. The scale bar is $5 \mu \mathrm{m}$. (b,c) Comparative XPS analysis of C1s, S2p, and O1s for the pristine and the SEI-coated graphite electrode with cycling. (d) FTIR analysis of solvent, solute, and fresh and residual electrolyte with and without DTD additives. (e) ${ }^{13}$ C NMR and (f) ${ }^{1} \mathrm{H}$ NMR spectroscopy of fresh and residual electrolyte, demonstrating the existence of residual DTD. (g) Quantitative analysis of DTD in residual electrolyte vs the number of cycles, where the residual DTD is measured by ${ }^{1} \mathrm{H}$ NMR spectroscopy based on the molar ratio of PC/ DTD.

without any electrolyte decomposition. This result shows that the SEI exists on the graphite surface and plays a role in preventing further decomposition of the electrolyte. The dQ/ $\mathrm{d} V$ analysis and cyclic voltammetry $(\mathrm{CV})$ results further corroborate this conclusion (Figures S5 and S6). These results confirm the existence of SEI on the graphite surface (Figure S7), but unfortunately, the SEI cannot mitigate the continuous electrolyte reduction, and it is insufficient to inhibit the $\mathrm{Li}^{+}-$ solvent co-intercalation and graphite exfoliation if there is no DTD additive in the electrolyte (Figures 1e and S1C). In brief, the SEI can be preserved well without partial dissolution during the disassembly and reassembly of the battery. The capability of SEI inhibiting the graphite exfoliation depends on whether there is sufficient DTD additive in the electrolyte. The critical factor to affect the graphite performance (e.g., $\mathrm{Li}^{+}$ (de)intercalation or $\mathrm{Li}^{+}$-solvent insertion) is actually the electrolyte composition. Thus, the partial dissolution of SEI cannot cause the exfoliation, but it can be judged from the electrolyte decomposition. We also confirm that these observations are general and exist in other kinds of carbonateand ether-based electrolytes (Figure S8). Taken together, these results inspired us to reconsider the conventional wisdom that the role of additives is to improve graphite stability by acting as SEI-forming agents.

Residual Additive in Electrolyte. In the past 2 decades, many kinds of additives (e.g., vinylene carbonate (VC), ${ }^{11} \mathrm{LiBOB},{ }^{17}$ metal ions, ${ }^{25,28}$ sodium or potassium salts, ${ }^{19,51}$ vinyl ethylene sulfite (VES), ${ }^{22}$ prop-1-ene-1,3-sultone, ${ }^{24,29}$ sulfur trioxide, ${ }^{27}$ phosphoric ester, ${ }^{52}$ tris(trimethylsilyl) phosphite, ${ }^{53}$ and furanone $^{54}$ ) have been commonly used as SEI film-forming agents, ${ }^{11-32,52-54}$ which can protect the graphite anode and guarantee the reversible $\mathrm{Li}^{+}$(de)intercalation within graphite (Table S1). However, the consumed amount of additives during battery cycling has been ignored, even though the concentration of most commonly used additives is at least $\sim 0.3$ $\mathrm{M}$ when converted from weight percent (or volume ratio) to molar concentration (Table S2). This value is even much higher than that of lithium salt in the electrolyte (e.g., $2.64 \mathrm{M}$ VES vs $\left.1.0 \mathrm{M} \mathrm{LiPF}_{6}\right)^{22}$ in the case of PC-based electrolyte (Table S2). Herein, we find that the amount of consumed additive such as DTD during the repeated (dis-)charge process is highly limited. The first piece of evidence for this conclusion is the lack of SEI variation with cycling (Figures S9-S11). We find that the SEI forms fast on the graphite surface in the initial cycles, and then, there is no obvious variation in its weight, morphology, or composition (Figures 2a and S10). The features of SEI formed in the PC-based electrolyte with DTD are also compared to SEI formed in commercial EC-based electrolytes (see details in Figure S12). In addition, we confirm that the amount of consumed DTD additive cannot exceed $1.1 \%$, which is estimated based on the measured SEI variation (see details in Figure S10). X-ray photoelectron spectroscopy (XPS) analysis further confirms this phenomena. The intensities, shapes, and fitting of C1s, S2p, and O1s peaks of the graphite electrode in Figure $2 b, c$ show clear change in the first cycle compared to the pristine state, demonstrating the formation of SEI in the first cycle. Thereafter, the variation is small, as further confirmed by the spectra of F1s and P2p (Figure S11). This result demonstrates that the DTD may be involved in SEI formation only in the initial cycles without 

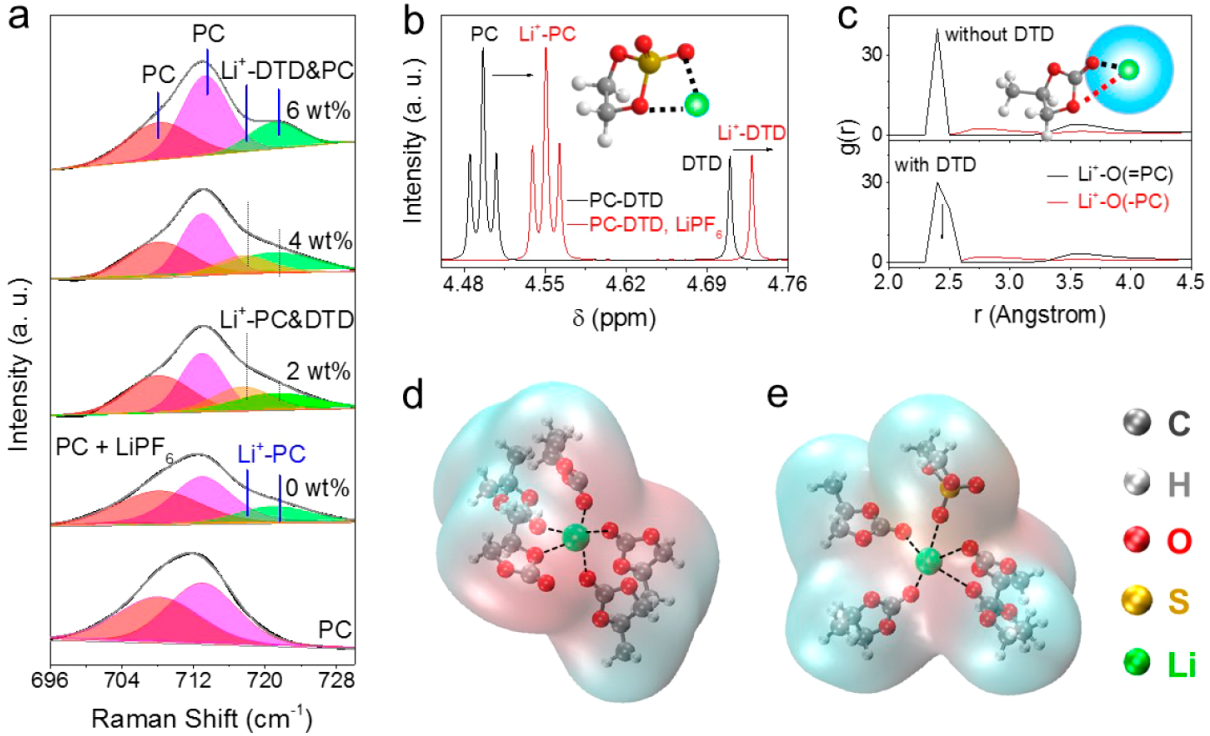

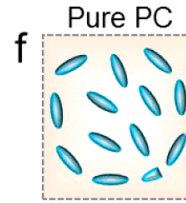

$[\mathrm{PC}]_{12.56}$

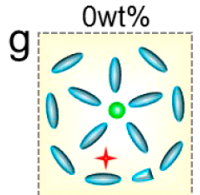

$\mathrm{Li}^{+}[\mathrm{PC}]_{12.56}\left[\mathrm{PF}_{6}{ }^{-}\right]$
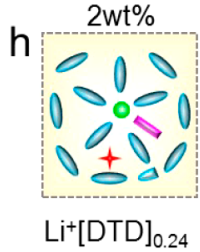

$[\mathrm{PC}]_{12.56}\left[\mathrm{PF}_{6}-{ }^{-}\right]$

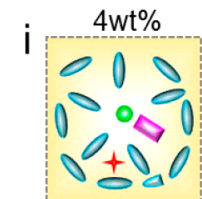

$\mathrm{Li}^{+}[\mathrm{DTD}]_{0.48}$

$[\mathrm{PC}]_{12.56}\left[\mathrm{PF}_{6}^{-}\right]$

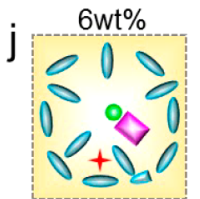

$\mathrm{Li}^{+}[\mathrm{DTD}]_{0.73}$

$[\mathrm{PC}]_{12.56}\left[\mathrm{PF}_{6}{ }^{-}\right]$

$\bigcirc \mathrm{PC} \circ \mathrm{Li}^{+} \stackrel{+}{\mathrm{PF}_{6}^{-}} \square[\mathrm{DTD}]_{0.24}$

$[\mathrm{DTD}]_{0.48}$

[DTD $]_{0.73}$

Figure 3. Coordination structure of $\mathrm{Li}^{+}$ions affected by additives in carbonate-based electrolyte. (a) Raman spectrum variation of PC with increasing concentration of DTD additives in electrolyte. The description of " $\mathrm{Li}^{+}-\mathrm{PC} \& D T D$ " or " $\mathrm{Li}^{+}-\mathrm{DTD} \& \mathrm{PC}$ " means that the DTD molecules can replace the PC molecules in the $\mathrm{Li}^{+}$clusters. The DTD can gradually replace the PC solvent in the $\mathrm{Li}^{+}$cluster $\left(\mathrm{i} . e ., \mathrm{Li}^{+}-\right.$ $\mathrm{PC} \& D T D$ ) and finally dominate the cluster environment (i.e., $\mathrm{Li}^{+}-\mathrm{DTD} \& \mathrm{PC}$ ), weakening the $\mathrm{Li}^{+}-\mathrm{PC}$ interactions and releasing the free $\mathrm{PC}$ in electrolyte. (b) Comparative ${ }^{1} \mathrm{H}$ NMR spectroscopy of PC/DTD with and without $\mathrm{LiPF}_{6}$. The inset shows the interaction of $\mathrm{Li}^{+}$and oxygen atoms in DTD. (c) Radial distribution function (RDF) of $\mathrm{Li}^{+}$to the oxygens in PC without and with DTD additives. The inset shows the schematic interactions of $\mathrm{Li}^{+}$with oxygens in PC in and near the first solvation shell (light blue area). Snapshot of $\mathrm{Li}^{+}$'s first solvation shell (d) without and (e) with DTD additives, where the DTD can replace the PC solvent in the first solvation shell. The results are consistent with those observed in Raman spectra. $(\mathrm{f}-\mathrm{j})$ Schematic illustration of the molecular interaction between carbonate solvent $(\mathrm{PC})$, $\mathrm{LiPF}_{6}$ solute, and DTD additives.

further consumption afterward; this conjecture is based on the analysis of SEI formed on the electrode, which is further proved by the presence of DTD in the residual electrolyte. The existence of DTD in residual electrolyte after cycling is confirmed by FTIR spectra, which show adsorption peaks of $\mathrm{S}=\mathrm{O}\left(\sim 1212\right.$ and $\left.1015 \mathrm{~cm}^{-1}\right)$ and S-O $\left(\sim 917 \mathrm{~cm}^{-1}, 650\right.$ $\mathrm{cm}^{-1}$ ) stretch vibrations belonging to the typical sulfate (Figures $2 \mathrm{~d}$ and S13). The residual DTD and its concentration were quantitatively determined by ${ }^{13} \mathrm{C}$ NMR and ${ }^{1} \mathrm{H}$ NMR (Figures $2 \mathrm{e}-\mathrm{g}$ and $\mathrm{S} 14-\mathrm{S} 17$ and Tables S3 and S4). The results in Figure $2 \mathrm{f}$ show that more than 5 wt \% DTD still exists in the residual electrolyte, even after prolonged cycling (Figures S14-S17 and Table S3). In addition, we find that the consumed DTD is highly limited when a fresh electrolyte with 6 wt \% DTD is used to assemble a new battery using the SEIcoated graphite (Figure S18). This result also confirms that the SEI is maintained on the graphite surface and the DTD additive affects the electrolyte properties and suppresses decomposition. Thus, we have to reconsider that the real reason for the enhanced graphite stability after adding the additives is the change in electrolyte chemistry, rather than the SEI film-forming effect, as previously believed. ${ }^{17-32}$ In addition, the change in SEI upon cycling was further confirmed by transmission electron microscopy (TEM) (Figure S19), showing consistent behavior with the SEM and XPS results (Figures 2 and S9-S12). The data collectively confirm our viewpoint about the SEI and electrolyte additive roles in graphite stability (Figure S19).

Coordinative Role of Additive. An insight into the electrolyte coordination chemistry can be gained from the Raman spectroscopy analysis of PC-based electrolyte containing different DTD concentrations. First, it is observed that the fitted peaks at around 718 and $721 \mathrm{~cm}^{-1}$, assigned to the asymmetric ring deformation of PC molecules ${ }^{55}$ (Figure S20), decrease in amount and shift to higher wavenumbers once the $\mathrm{LiPF}_{6}$ salt is dissolved. We attribute this to the formation of $\mathrm{Li}^{+}-\mathrm{PC}$ clusters and the decreased concentration of free PC molecules in the electrolyte (i.e., $\mathrm{Li}^{+}[\mathrm{PC}]_{12.56}\left[\mathrm{PF}_{6}^{-}\right]$). Upon adding DTD into the electrolyte (below $6 \mathrm{wt} \% \mathrm{DTD}$ ), the peaks of $\mathrm{Li}^{+}-\mathrm{PC}$ become broad because of the varied interactions of $\mathrm{Li}^{+}-\mathrm{DTD}$ and $\mathrm{Li}^{+}-\mathrm{PC}$ within the $\mathrm{Li}^{+}$cluster (i.e., $\left.\mathrm{Li}^{+}-\mathrm{PC} \& \mathrm{DTD}\right)$, where the DTD molecule can competitively coordinate with $\mathrm{Li}^{+}$(i.e., $\left.\mathrm{Li}^{+}[\mathrm{DTD}]_{x}[\mathrm{PC}]_{12.56}\left[\mathrm{PF}^{-}\right]_{6}, x=0,0.24,0.48,0.73\right)$. An 


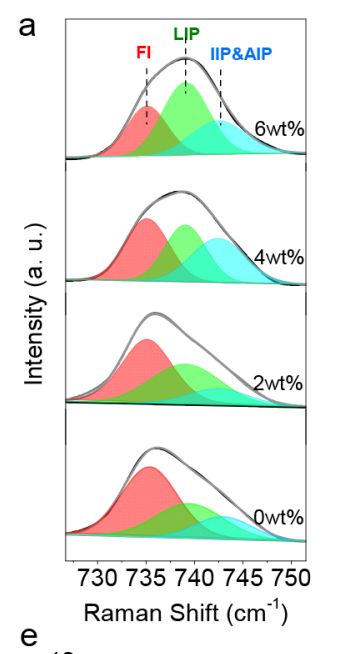

e
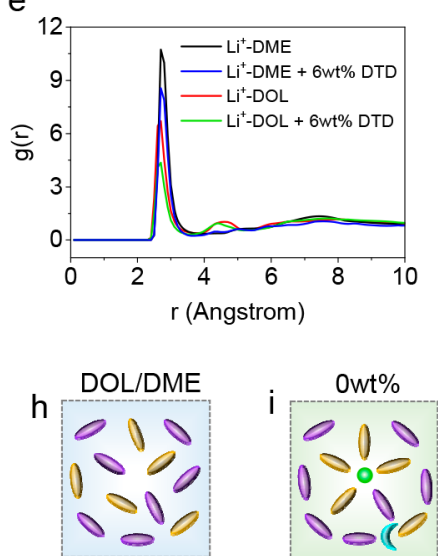

$[\mathrm{DME}]_{4.94}[\mathrm{DOL}]_{7.36}$

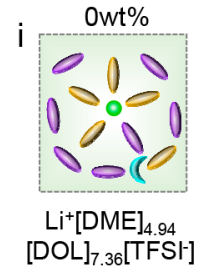

$\Leftrightarrow$ DOL $\Leftrightarrow$ DME $\circ \mathrm{Li}^{+}$
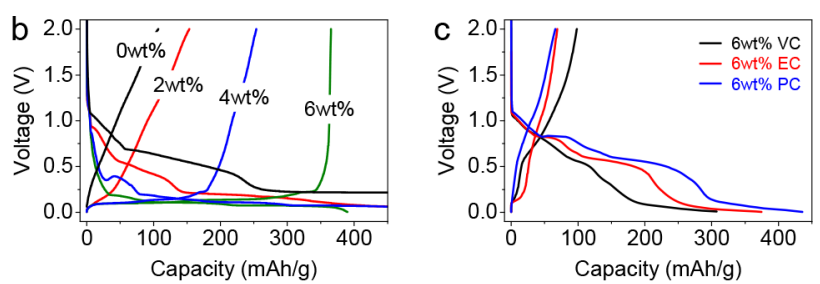

d
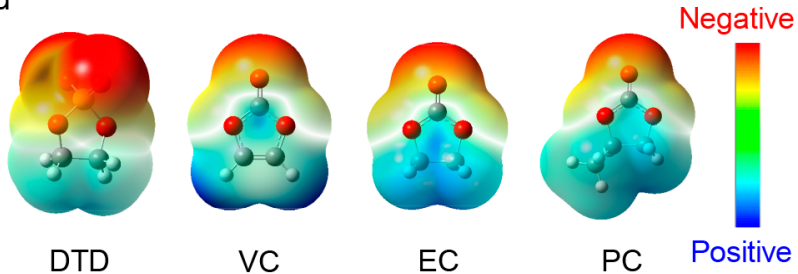

EC
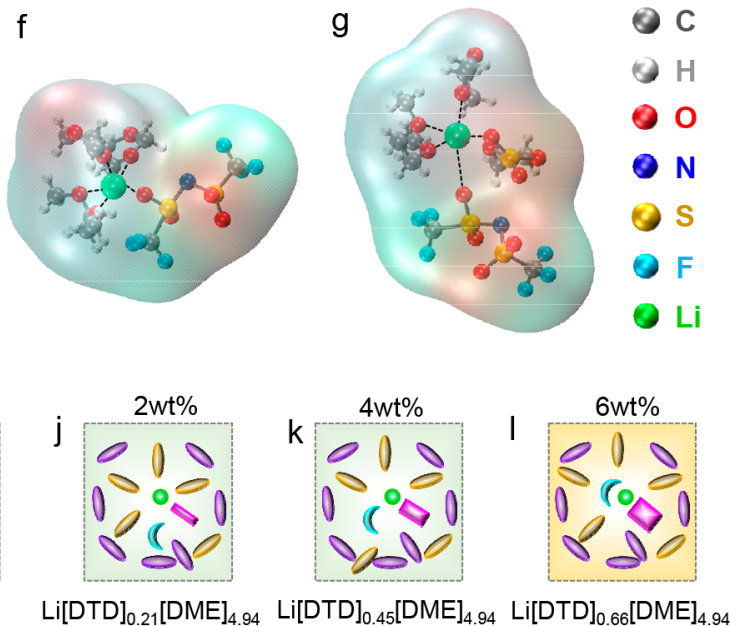

$\left[\mathrm{DOL}_{7.36}\left[\mathrm{TFSI}^{-}\right] \quad[\mathrm{DOL}]_{7.36}\left[\mathrm{TFSI}^{-}\right] \quad[\mathrm{DOL}]_{7.36}\left[\mathrm{TFSI}^{-}\right]\right.$

( TFSI-

$\square[\mathrm{DTD}]_{0.22}$

$[\mathrm{DTD}]_{0.45}$

$[\mathrm{DTD}]_{0.66}$

Figure 4. Coordinative role of additives in ether-based electrolyte for graphite stability. (a) Raman spectrum variation of electrolyte with increasing concentration of additives. Voltage vs capacity profile of the graphite electrode in the electrolyte of 1.0 M LiTFSI in DOL/DME with (b) varied concentration of DTD and (c) other kinds of additives in the first cycle. (d) Comparative electrostatic potential surface of additives. (e) RDF of $\mathrm{Li}^{+}$to the oxygen of ether solvent with and without the DTD additives. The frequency of ether solvent that appeared in the first $\mathrm{Li}^{+}$solvation shell decreases, indicating that the $\mathrm{Li}^{+}$-ether interaction can be weakened by adding DTD. (f,g) Snapshot of the first solvation shell of $\mathrm{Li}^{+}$ions without and with DTD additives, where the DTD can replace the ether solvent in the first solvation shell. (h-l) Schematic illustration of molecular interaction between the ether-based solvent (DOL/DME), the solute of LiTFSI, and DTD additives.

obvious separation of $\mathrm{Li}^{+}$clusters and free PC appears when the D T D increases to 6 wt \% (i.e., $\left.\mathrm{Li}^{+}[\mathrm{DTD}]_{0.73}[\mathrm{PC}]_{12.56}\left[\mathrm{PF}_{6}^{-}\right]\right)$. This result demonstrates that the DTD mainly dominates the coordinative situation of $\mathrm{Li}^{+}$ clusters (i.e., $\mathrm{Li}^{+}-\mathrm{DTD} \& \mathrm{PC}$ ), where the strength and number of $\mathrm{Li}^{+}-\mathrm{PC}$ units in the $\mathrm{Li}^{+}$clusters becomes weaker and decreases (Figure 3a), thereby releasing a large amount of free PC. In brief, the $\mathrm{Li}^{+}$clusters can change from the $\mathrm{Li}^{+}-\mathrm{PC}$ to $\mathrm{Li}^{+}-\mathrm{PC} \& D T D$ or $\mathrm{Li}^{+}-\mathrm{DTD} \& \mathrm{PC}$ when the amount of added DTD increases in the electrolyte. This conclusion is supported by the ${ }^{1} \mathrm{H}$ NMR analysis (Figure $3 \mathrm{~b}$ ), which shows that the $\mathrm{H}$ chemical shift in DTD moves to a higher wavenumber and thus confirms the coordination of DTD with $\mathrm{Li}^{+}$in the electrolyte.

This observation is further supported by large-scale molecular dynamics (MD) simulation (details shown in the Supporting Information). In general, the $\mathrm{Li}^{+}$cation can dissolve well in PC solvent and may have 4-6 neighbors mainly consisting of the solvent molecules. ${ }^{2}$ After adding $6 \mathrm{wt}$ $\%$ DTD into the solvent, DTD may replace some solvent molecules and participate in constructing the first solvation shell of the central $\mathrm{Li}^{+}$cation. The replaced solvent molecules exhibit features that belong to the "free solvent", leading to an obvious separation in peaks in the Raman spectrum from free solvent to the coordinated ones in $\mathrm{Li}^{+}$clusters (i.e., $\mathrm{Li}^{+}-$ DTD\&PC, $\left.\mathrm{Li}^{+}[\mathrm{DTD}]_{0.73}[\mathrm{PC}]_{12.56}\left[\mathrm{PF}_{6}^{-}\right]\right)$. The reduced frequency of PC molecules within the $\mathrm{Li}^{+}$first solvation shell after adding 6 wt \% DTD confirms the results in Figure 3c. The snapshot in Figure 3d,e shows the simulated $\mathrm{Li}^{+}$solvation structure with and without DTD in the electrolyte. It can be seen that the DTD can indeed act as a coordinator and replace PC molecules, thereby changing the $\mathrm{Li}^{+}$solvation structure. Thus, a schematic illustration of molecular interaction among $\mathrm{PC}, \mathrm{LiPF}_{6}$, and the varied amount of DTD additives is further shown in Figure $3 \mathrm{f}-\mathrm{j}$ to make the $\mathrm{Li}^{+}$-solvent interaction clear. The decreased interaction of $\mathrm{Li}^{+}$-solvent can make the $\mathrm{Li}^{+}$(de)intercalation much easier within graphite, thus avoiding the exfoliation problem caused by the $\mathrm{Li}^{+}$-solvent co-intercalation and giving rise to good stability of graphite. 
This point is further confirmed by the fact that increasing the DTD to 12 wt \% (i.e., $\mathrm{Li}^{+}[\mathrm{DTD}]_{1.46}[\mathrm{PC}]_{12.56}\left[\mathrm{PF}_{6}{ }^{-}\right]$) also stabilizes graphite due to the reduced $\mathrm{Li}^{+}-$solvent (i.e., $\mathrm{Li}^{+}-$ PC) interactions (Figure S21). In addition, the lithium cation transference number decreases with the increasing amount of DTD in the electrolyte, which corroborates the stronger interaction of $\mathrm{Li}^{+}-\mathrm{DTD}$ compared to $\mathrm{Li}^{+}-\mathrm{PC}$ (Figure S22). Note that the additive molecules could also provide better coordination structure to prevent the decomposition of solvents. This is because the electrolyte decomposition and the consumption of DTD are highly limited when a fresh electrolyte with 6 wt \% DTD is used to assemble a new battery with SEI-coated graphite (Figure 1e, black curve, Figure S18). In contrast, there is a serious electrolyte decomposition in DTD-free electrolyte (e.g., 1.0 $\mathrm{M} \mathrm{LiPF}_{6}$ in PC). This is true even when SEI-coated graphite is used in a new battery (Figure le, red curve).

Applicability from Ester- to Ether-Based Electrolyte. Our proposed mechanism is further shown to work in etherbased electrolyte, in which the $\mathrm{Li}^{+}$-solvent co-insertion is also suppressed by adding additives. For example, we examined the typical electrolyte 1.0 M LiTFSI in DOL/DME used in Li-S batteries, ${ }^{56-58}$ in which the layered graphite structure is always exfoliated by the $\mathrm{Li}^{+}$-solvent co-intercalation in the first cycle. ${ }^{59}$ When we introduce up to 6 wt \% DTD additive in the ether-based electrolyte, there is an obvious Raman shift to higher wavenumbers for the $\mathrm{S}-\mathrm{N}-\mathrm{S}$ bending vibration of TFSI $^{-}$ions, as shown in the Raman spectra in Figure 4a. This result demonstrates that the interactions of $\mathrm{Li}^{+}-\mathrm{TFSI}^{-}$are strong and that DTD can replace the ether solvent molecules to make contact with $\mathrm{Li}^{+}$ $\left(\mathrm{Li}^{+}[\mathrm{DTD}]_{x}[\mathrm{DME}]_{4.94}[\mathrm{DOL}]_{7.36}\left[\mathrm{TFSI}^{-}\right], x=0,0.21,0.45\right.$, $0.66)$. Direct proof of this conclusion is the reduced amount of free $\mathrm{TFSI}^{-}$ions (FI) and the increased amount of loose ion pair (LIP) and intimate ion pair (IIP) \& aggregated ion pair (AIP), ${ }^{60}$ as shown in Figure S23. Note that the ratio of (LIP/ IIP\&AIP)/FI increases from 0.89 to 2.56 when the DTD increases to $6 \mathrm{wt} \%$. In this way, the strength of $\mathrm{Li}^{+}$-solvent interaction can be largely reduced, and finally, the $\mathrm{Li}^{+}$is expected to be (de)intercalated into the graphite without $\mathrm{Li}^{+}-$ solvent co-insertion. This proposed mechanism is consistent with the results observed in the discharge curves of graphite in a lithium battery, where the reversible capacity of graphite increases and reaches normal values when the DTD content is around 6 wt \% (Figure 4b). In addition, the lithium cation transference number decreases with increasing amount of DTD; this trend corroborates the stronger interaction of $\mathrm{Li}^{+}-$ DTD compared to $\mathrm{Li}^{+}$-ether solvent (Figure S24). Interestingly, this is the same trend observed in PC-based electrolyte. We specifically note that this is the first demonstration that additives in ether-based electrolyte can stabilize graphite and successfully prevent the well-known graphite exfoliation problem (Table S5). ${ }^{39,43,46,61-67}$

Coordination Capability of Additives and Its Universality. By changing the type of additive, we can further illustrate its role as a coordinator that changes the $\mathrm{Li}^{+}$solvation structure in electrolytes. Figure $4 c$ shows the electrostatic potential on the surface of different species, which is broadly used as a qualitative measure of cation $-\pi$ interactions. ${ }^{68-70}$ In general, DTD has two highly negative $\mathrm{S}=\mathrm{O}$ bonds, and it can strongly bind to $\mathrm{Li}^{+}$cations. On the other hand, the generally used VC additives have relatively weaker columbic interactions with the positive lithium cations and hence are expected to weakly bind to $\mathrm{Li}^{+}$cations. This is in fact confirmed in PC-based electrolyte, where DTD can make the electrolyte work well, but $\mathrm{VC}$ always fails, even when the amount of $\mathrm{VC}$ is increased from 6 to 12 wt \% (i.e., $\mathrm{Li}^{+}[\mathrm{VC}]_{x}[\mathrm{PC}]_{12.56}\left[\mathrm{PF}^{-}\right]_{6}, x=1.06$, 2.12, Figure S25). Similarly, the vinyl ethylene carbonate (VEC) additive ${ }^{4,71}$ does not improve graphite stability in PCbased electrolyte either (Figure S26). This is because the coordination ability of VC and VEC is insufficient to compete with PC. Moreover, ether-based electrolyte using additives with weaker coordination capability, such as VC, EC, and PC, has more serious electrolyte decomposition and $\mathrm{Li}^{+}$-solvent intercalation (i.e., graphite exfoliation) within the voltage range of $1.0-0.1 \mathrm{~V}$ (Figure 4c), which further confirms the importance of additives' coordination capability (Figure 4d). These results are confirmed by simulations. Specifically, we can see that the frequency of ether-based solvent appearing around $\mathrm{Li}^{+}$is significantly reduced when the DTD additives are added into the electrolyte (Figure 4e). One typical snapshot in Figure $4 \mathrm{f}, \mathrm{g}$ clearly shows that the ether solvent can be replaced by DTD, leading to weaker $\mathrm{Li}^{+}-$solvent interactions. Thus, a schematic illustration of molecular interaction among DOL/ DME, LiTFSI, and the varied amount of DTD additives is further shown in Figure $4 \mathrm{~h}-1$ to make the $\mathrm{Li}^{+}$-solvent interaction variation clear. In addition, the $\mathrm{Li}^{+}$-solvent interaction is further presented in Figure $5 a-c$ when different additives (e.g., VC, EC, or PC) were used in the electrolyte of 1.0 $\mathrm{M} \mathrm{LiPF}_{6}$ in PC or 1.0 M LiTFSI in DOL/DME. On the basis of these results, we present an alternative viewpoint that brings significant new insight regarding the stability of graphite in super-high-concentrated electrolyte systems. ${ }^{43-49,72}$ In these systems, full aggregation of $\mathrm{Li}^{+}$-solvent and protection of SEI are considered to be necessary to suppress the $\mathrm{Li}^{+}-$solvent cointercalation and stabilize the graphite. Our results show that the decreased $\mathrm{Li}^{+}$-solvent interaction at higher salt concentrations or the weaker coordination capacity of solvents may be the root cause of graphite stabilization. In other words, the SEI effect may not be the most critical factor, and full aggregation may not be necessary, if the $\mathrm{Li}^{+}$-solvent interaction can be weakened enough by strong coordinative additives (e.g., DTD).

In addition, we studied the additive effect in relation to the popular concentrated electrolyte concept. We found that the ratio of solvent $/ \mathrm{Li}^{+}$in concentrated electrolyte is only about 1-3 (i.e., $\mathrm{Li}^{+}[\text {solvent }]_{1-3}[$ anion $]$, Figures $5 \mathrm{~d}-\mathrm{g}$ and S27), ${ }^{39,43-49,72}$ which is much lower than the number (1213 ) in our present electrolyte (e.g., $\left.\mathrm{Li}^{+}[\mathrm{DTD}]_{x}[\mathrm{PC}]_{12.56}\left[\mathrm{PF}^{-}\right]_{6}\right)$ and in commercial electrolyte (e.g., $\mathrm{Li}^{+}[\mathrm{EC}]_{7.49}[\mathrm{DEC}]_{4.12}\left[\mathrm{PF}_{6}^{-}\right], 1.0 \mathrm{M} \mathrm{LiPF}_{6}$ in EC/DEC). This means that more lithium salt is used in concentrated electrolyte. Thus, the popular (superhigh) concentrated electrolyte concept and the additive effect in presented electrolyte systems represent different ways of changing the $\mathrm{Li}^{+}$solvation structure (e.g., $\mathrm{Li}^{+}-$solvent interaction). We are therefore able to change the $\mathrm{Li}^{+}-$solvent interactions by the additive effect, which allows us to reduce the concentration of electrolyte to achieve comparable or even better performances at much lower cost. To provide further evidence for our hypothesis, we examine the ether-based electrolyte used in $\mathrm{Li}-$ $\mathrm{O}_{2}$ batteries with tetraethylene glycol dimethyl ether $(\text { TEGDME) })^{38}$ as solvent. Here again, we find that the graphite can be stabilized at around $355 \mathrm{mAh} \mathrm{g}^{-1}$ using the DTD additive (Figure S28), where the $\mathrm{Li}^{+}$-solvent interaction becomes weakened due to the presence of DTD additive 


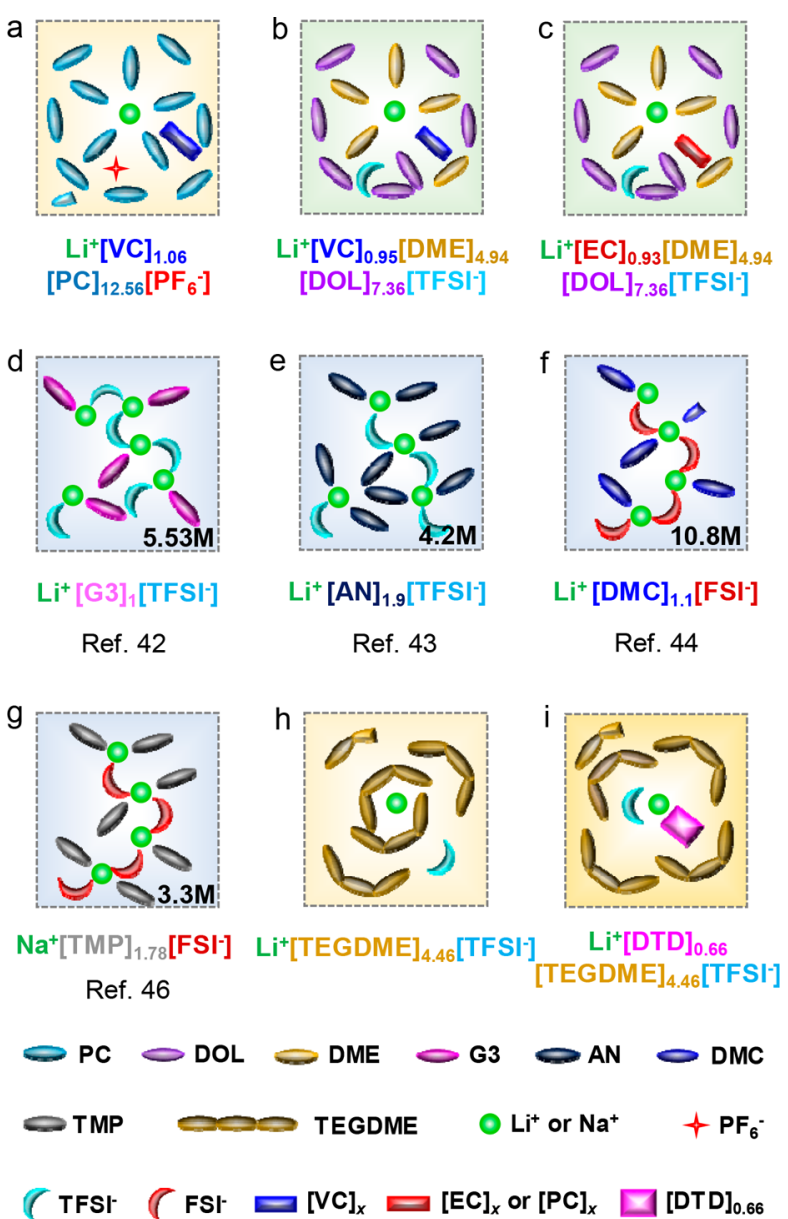

Figure 5. Schematic illustration of molecular interaction between solvent and solute in different systems. (a) $1.0 \mathrm{M} \mathrm{LiPF}_{6}$ in PC and $(b, c) 1.0 \mathrm{M}$ LiTFSI in DOL/DME using different kinds of additives with an amount of 6 wt \%. (d-g) Super-highconcentrated electrolyte reported before, in which no additive is used. (h,i) 1.0 M LiTFSI in TEGDME (h) with and (i) without 6 wt $\%$ DTD additive.

(Figure 5h,i, $\mathrm{Li}^{+}[\mathrm{DTD}]_{0.66}[\mathrm{TEGDME}]_{4.46}\left[\mathrm{TFSI}^{-}\right]$). On the basis of these results, it is easy to understand why using other carbonate solvents (e.g., EC, EMC, DMC, which could also be considered as additives) instead of PC in solvent can stabilize the graphite even using a smaller amount of additives (Table $\mathrm{S} 2)$. The reason is the changed $\mathrm{Li}^{+}-$solvent coordination structure with solvent and additives. Besides, we have to note that any soluble byproducts from the side-reactions (e.g., electrolyte decomposition, and/or dissolution of lithium $)^{12,73}$ can also affect the $\mathrm{Li}^{+}$solvation structure. Thus, more attention should be paid when the amount of byproduct reaches a value similar to that of additives (e.g., $>1 \mathrm{wt} \%$ ). In this study, the side-reactions in the electrolyte are very limited, judged from the initial (dis-)charge curves (i.e., Coulombic efficiency) (Figure 1c,e); thus, we believe that the byproduct effects could be ignored.

Thus, the additive's coordinator role in different kinds of electrolytes is demonstrated systematically in electrolyte systems commonly used in $\mathrm{Li}$-ion, $\mathrm{Li}-\mathrm{S}$, and $\mathrm{Li}-\mathrm{O}_{2}$ batteries (Figure 6). The proposed coordinator role of additives in ester- (i.e., carbonate) and ether-based electrolytes offers a new way to optimize metal-ion batteries using different solvents (e.g., sulfoxide, sulfone, nitriles, phosphorus, or silicon-based

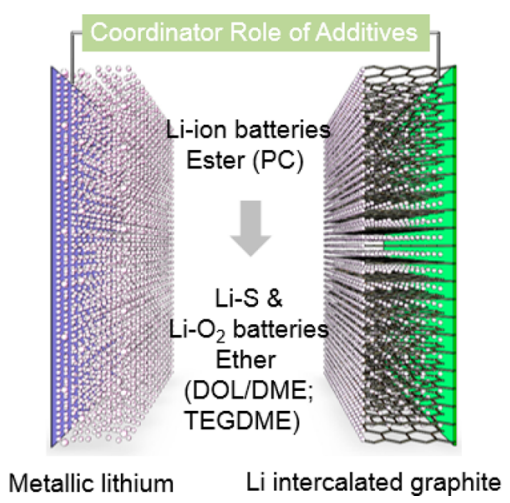

Figure 6. Confirmation of the coordinative role of additives in different types of electrolytes toward the stability of graphite anodes. The coordinative role of additives in electrolytes is proven in ester- and ether-based electrolytes, which are widely used in lithium-ion, $\mathrm{Li}-\mathrm{S}$, and $\mathrm{Li}-\mathrm{O}_{2}$ batteries.

solvent), additives, or salts in the electrolyte (Figure S29). ${ }^{2,30,74,75}$ Furthermore, the $\mathrm{Li}^{+}$-solvent interaction model proposed here can facilitate the study of desolvation behavior of other cations (e.g., $\mathrm{Li}^{+}, \mathrm{Na}^{+}, \mathrm{K}^{+}, \mathrm{Mg}^{2+}, \mathrm{Al}^{3+}$, etc.) on electrode surfaces, which can help to interpret the electrochemical performance in the molecular-scale approach.

In summary, we have demonstrated that the variation of $\mathrm{Li}^{+}$ solvation structure with additives has a significant effect on graphite stability, which is different from the commonly believed SEI film-forming additive effect. The additives can in fact act as coordinators, changing the $\mathrm{Li}^{+}$coordination structure and the interactions of $\mathrm{Li}^{+}$-solvent pairs in the electrolyte. Thus, the competitive $\mathrm{Li}^{+}$(de)intercalation or $\mathrm{Li}^{+}-$ solvent co-insertion within graphite can be tuned by the concentration of salt, additive chemistry, or solvent composition. This new discovery is confirmed both in commonly used carbonate and ether-based electrolytes and provides deeper insight into understanding the role of additives. We further surmise that the coordination chemistry of electrolytes may be the root cause of this enhanced battery performance as it can affect the electrolyte and electrode behavior. This work provides significant insight that can be used to improve mobile ion battery systems.

\section{ASSOCIATED CONTENT}

\section{Supporting Information}

The Supporting Information is available free of charge on the ACS Publications website at DOI: 10.1021/acsenergylett.9b01441.

Experimental and simulation section, figures showing additive effects and the role of SEI in graphite anode stability and electrochemical behavior, characterization of charged graphite anodes and the SEI effect on graphite, characterization of SEI in electrolytes with additives, XPS analysis, Fourier-transform infrared spectroscopy of the electrolyte, NMR analysis of additives and solvents, characterization of the amount of additives and solvents, Raman spectra, characterization of the effect of the transference number, coordination details, schematic illustration of molecular interaction between solvent and solute, and schematic view of atomic name definitions, and tables presenting a summary of typical electrolyte additives to stabilize the 
graphite anode, a summary of the concentration of additives reported in lithium ion batteries, comparative molar ratios, determination of solvent and additive residuals, strategies for stabilizing the graphite anode, partial charges for each type of atom, Lennard-Jones parameters for each type of atom, bonding parameters for each type of molecule, and experimental density parameters (PDF)

\section{AUTHOR INFORMATION}

\section{Corresponding Authors}

*E-mail: lance.li@kaust.edu.sa (L.L.).

*E-mail: yksun@hanyang.ac.kr (Y.K.S.).

*E-mail: husam.alshareef@kaust.edu.sa (H.A.).

ORCID

Jun Ming: 0000-0001-9561-5718

Luigi Cavallo: 0000-0002-1398-338X

Yang-Kook Sun: 0000-0002-0117-0170

Husam N. Alshareef: 0000-0001-5029-2142

\section{Author Contributions}

${ }^{\perp}$ J.M., Z.C., and Y.W. contributed equally. The manuscript was written through the contributions of all authors. All authors have given approval to the final version of the manuscript.

Notes

The authors declare no competing financial interest.

\section{ACKNOWLEDGMENTS}

The research reported in this publication was supported by the National Natural Science Foundation of China (21978281) and King Abdullah University of Science and Technology (KAUST). The authors also acknowledge fruitful discussions with the research scientists at Huzhou Kunlun Power Battery Materials Co., LTD.

\section{REFERENCES}

(1) Tarascon, J. M.; Armand, M. Issues and Challenges Facing Rechargeable Lithium Batteries. Nature 2001, 414, 359-367.

(2) $\mathrm{Xu}, \mathrm{K}$. Electrolytes and Interphases in Li-Ion Batteries and Beyond. Chem. Rev. 2014, 114, 11503-11618.

(3) Li, W.; Yao, H.; Yan, K.; Zheng, G.; Liang, Z.; Chiang, Y. M.; Cui, Y. The Synergetic Effect of Lithium Polysulfide and Lithium Nitrate to Prevent Lithium Dendrite Growth. Nat. Commun. 2015, 6, 7436.

(4) Xia, J.; Dahn, J. R. Improving Sulfolane-Based Electrolyte for High Voltage Li-Ion Cells with Electrolyte Additives. J. Power Sources 2016, 324, 704-711.

(5) Xia, J.; Nelson, K. J.; Lu, Z. H.; Dahn, J. R. Impact of Electrolyte Solvent and Additive Choices on High Voltage Li-Ion Pouch Cells. J. Power Sources 2016, 329, 387-397.

(6) Zheng, J. M.; Engelhard, M. H.; Mei, D. H.; Jiao, S. H.; Polzin, B. J.; Zhang, J. G.; Xu, W. Electrolyte Additive Enabled Fast Charging and Stable Cycling Lithium Metal Batteries. Nat. Energy 2017, 2, 17012.

(7) Li, G. X.; Gao, Y.; He, X.; Huang, Q. Q.; Chen, S. R.; Kim, S. H.; Wang, D. H. Organosulfide-Plasticized Solid-Electrolyte Interphase Layer Enables Stable Lithium Metal Anodes for Long-Cycle LithiumSulfur Batteries. Nat. Commun. 2017, 8, 850.

(8) Ma, L.; Ellis, L.; Glazier, S. L.; Ma, X. W.; Dahn, J. R. Combinations of $\mathrm{LiPO}_{2} \mathrm{~F}_{2}$ and Other Electrolyte Additives in $\mathrm{Li}\left[\mathrm{Ni}_{0.5} \mathrm{Mn}_{0.3} \mathrm{Co}_{0.2}\right] \mathrm{O}_{2} /$ Graphite Pouch Cells. J. Electrochem. Soc. 2018, 165, A1718-A1724.

(9) Ma, L.; Xia, J.; Xia, X.; Dahn, J. R. The Impact of Vinylene Carbonate, Fluoroethylene Carbonate and Vinyl Ethylene Carbonate Electrolyte Additives on Electrode/Electrolyte Reactivity Studied using Accelerating Rate Calorimetry. J. Electrochem. Soc. 2014, 161, A1495-A1498.

(10) McMillan, R.; Slegr, H.; Shu, Z. X.; Wang, W. D. Fluoroethylene Carbonate Electrolyte and Its Use In Lithium Ion Batteries with Graphite Anodes. J. Power Sources 1999, 81, 20-26.

(11) Aurbach, D.; Gamolsky, K.; Markovsky, B.; Gofer, Y.; Schmidt, M.; Heider, U. On the Use of Vinylene Carbonate (VC) Electrolyte Solutions for Li-Ion as an Additive to Batteries. Electrochim. Acta 2002, 47, 1423-1439.

(12) Mogi, R.; Inaba, M.; Jeong, S. K.; Iriyama, Y.; Abe, T.; Ogumi, Z. Effects of Some Organic Additives on Lithium Deposition in Propylene Carbonate. J. Electrochem. Soc. 2002, 149, A1578-A1583.

(13) Zhang, S. S. A Review on Electrolyte Additives for Lithium-Ion Batteries. J. Power Sources 2006, 162 (2), 1379-1394.

(14) Ochida, M.; Doi, T.; Domi, Y.; Tsubouchi, S.; Nakagawa, H.; Yamanaka, T.; Abe, T.; Ogumi, Z. Effects of Electrolyte Additives on the Suppression of Mn Deposition on Edge Plane Graphite for Lithium-Ion Batteries. J. Electrochem. Soc. 2013, 160, A410-A413.

(15) Dong, Y. N.; Demeaux, J.; Zhang, Y. Z.; Lucht, B. L. Improving the Performance of Graphite/ $\mathrm{LiNi}_{0.5} \mathrm{Mn}_{1.5} \mathrm{O}_{4}$ Cells with Added N,Ndimethylformamide Sulfur Trioxide Complex. J. Electrochem. Soc. 2017, 164, A3182-A3190.

(16) Xing, L. D.; Zheng, X. W.; Schroeder, M.; Alvarado, J.; von Wald Cresce, A.; Xu, K.; Li, Q. S.; Li, W. S. Deciphering the Ethylene Carbonate-Propylene Carbonate Mystery in Li-Ion Batteries. Acc. Chem. Res. 2018, 51, 282-289.

(17) Zhang, S. S.; Xu, K.; Jow, T. R. Enhanced Performance of LiIon Cell with $\mathrm{LiBF}_{4}-\mathrm{PC}$ based Electrolyte by Addition of Small Amount of LiBOB. J. Power Sources 2006, 156, 629-633.

(18) Zheng, H.; Li, B.; Fu, Y.; Abe, T.; Ogumi, Z. Compatibility of Quaternary Ammonium-based Ionic Liquid Electrolytes with Electrodes in Lithium Ion Batteries. Electrochim. Acta 2006, 52, 1556-1562.

(19) Zheng, H. H.; Fu, Y. B.; Zhang, H. C.; Abe, T.; Ogumi, Z. Potassium Salts-Electrolyte Additives for Enhancing Electrochemical Performances of Natural Graphite Anodes. Electrochem. Solid-State Lett. 2006, 9, A115-A119.

(20) Xu, M. Q.; Li, W. S.; Zuo, X. X.; Liu, J. S.; Xu, X. Performance Improvement of Lithium Ion Battery using PC as a Solvent Component and BS as an SEI Forming Additive. J. Power Sources 2007, 174, 705-710.

(21) Wang, B.; Qu, Q. T.; Xia, Q.; Wu, Y. P.; Li, X.; Gan, C. L.; Van Ree, T. Effects of 3,5-Bis(Trifluoromethyl)Benzeneboronic Acid as an Additive on Electrochemical Performance of Propylene CarbonateBased Electrolytes for Lithium Ion Batteries. Electrochim. Acta 2008, 54, 816-820.

(22) Yao, W. H.; Zhang, Z. R.; Gao, J.; Li, J.; Xu, J.; Wang, Z. C.; Yang, Y. Vinyl Ethylene Sulfite as a New Additive in Propylene Carbonate-based Electrolyte for Lithium Ion Batteries. Energy Environ. Sci. 2009, 2, 1102-1108.

(23) Sano, A.; Maruyama, S. Decreasing the initial Irreversible Capacity Loss by Addition of Cyclic Sulfate as Electrolyte Additives. J. Power Sources 2009, 192, 714-718.

(24) Li, B.; Xu, M. Q.; Li, T. T.; Li, W. S.; Hu, S. J. Prop-1-ene-1,3sultone as SEI formation Additive in Propylene Carbonate-Based Electrolyte for Lithium Ion Batteries. Electrochem. Commun. 2012, 17, 92-95.

(25) Takeuchi, S.; Yano, S.; Fukutsuka, T.; Miyazaki, K.; Abe, T. Electrochemical Intercalation/De-Intercalation of Lithium Ions at Graphite Negative Electrode in TMP-Based Electrolyte Solution. J. Electrochem. Soc. 2012, 159, A2089-A2091.

(26) Li, B.; Xu, M.; Li, B.; Liu, Y.; Yang, L.; Li, W.; Hu, S. Properties of solid Electrolyte Interphase formed by Prop-1-ene-1,3-Sultone on Graphite Anode of Li-Ion Batteries. Electrochim. Acta 2013, 105, 1-6.

(27) Demeaux, J.; Dong, Y. N.; Lucht, B. L. Reversible Graphite Anode Cycling with PC-Based Electrolytes Enabled by Added Sulfur Trioxide Complexes. J. Electrochem. Soc. 2017, 164, A1352-A1360.

(28) Chandrasiri, K. W. D. K.; Nguyen, C. C.; Zhang, Y. Z.; Parimalam, B. S.; Lucht, B. L. Systematic Investigation of Alkali Metal 
Ions as Additives for Graphite Anode in Propylene Carbonate Based Electrolytes. Electrochim. Acta 2017, 250, 285-291.

(29) Wang, K.; Xing, L.; Zhi, H.; Cai, Y.; Yan, Z.; Cai, D.; Zhou, H.; Li, W. High Stability Graphite/Electrolyte Interface Created by a Novel Electrolyte Additive: A Theoretical and Experimental Study. Electrochim. Acta 2018, 262, 226-232.

(30) $\mathrm{Xu}, \mathrm{K}$. Nonaqueous Liquid Electrolytes for Lithium-Based Rechargeable Batteries. Chem. Rev. 2004, 104, 4303-4417.

(31) Verma, P.; Maire, P.; Novak, P. A Review of the Features and Analyses of the Solid Electrolyte Interphase in Li-Ion Batteries. Electrochim. Acta 2010, 55, 6332-6341.

(32) Haregewoin, A. M.; Wotango, A. S.; Hwang, B. J. Electrolyte Additives for Lithium Ion Battery Electrodes: Progress and Perspectives. Energy Environ. Sci. 2016, 9, 1955-1988.

(33) Abe, T.; Fukuda, H.; Iriyama, Y.; Ogumi, Z. Solvated Li-Ion Transfer at Interface between Graphite and Electrolyte. J. Electrochem. Soc. 2004, 151, A1120-A1123.

(34) Yamada, Y.; Koyama, Y.; Abe, T.; Ogumi, Z. Correlation between Charge-Discharge Behavior of Graphite and Solvation Structure of the Lithium Ion in Propylene Carbonate-Containing Electrolytes. J. Phys. Chem. C 2009, 113, 8948-8953.

(35) Yamada, Y.; Iriyama, Y.; Abe, T.; Ogumi, Z. Kinetics of Lithium Ion Transfer at the Interface between Graphite and Liquid Electrolytes: Effects of Solvent and Surface Film. Langmuir 2009, 25, 12766-12770.

(36) Bruce, P. G.; Freunberger, S. A.; Hardwick, L. J.; Tarascon, J. M. Li- $\mathrm{O}_{2}$ and $\mathrm{Li}-\mathrm{S}$ Batteries with High Energy Storage. Nat. Mater. 2012, 11, 19-29.

(37) Harry, K. J.; Hallinan, D. T.; Parkinson, D. Y.; MacDowell, A. A.; Balsara, N. P. Detection of Subsurface Structures Underneath Dendrites formed on Cycled Lithium Metal Electrodes. Nat. Mater. 2014, 13, 69-73.

(38) Jung, H. G.; Hassoun, J.; Park, J. B.; Sun, Y. K.; Scrosati, B. An Improved High-Performance Lithium-Air Battery. Nat. Chem. 2012, $4,579-585$.

(39) Lv, D. P.; Yan, P. F.; Shao, Y. Y.; Li, Q. Y.; Ferrara, S.; Pan, H. L.; Graff, G. L.; Polzin, B.; Wang, C. M.; Zhang, J. G.; Liu, J.; Xiao, J. High Performance Li-Ion Sulfur Batteries enabled by Intercalation Chemistry. Chem. Commun. 2015, 51, 13454-13457.

(40) Yu, X. W.; Manthiram, A. Electrode-Electrolyte Interfaces in Lithium-Sulfur Batteries with Liquid or Inorganic Solid Electrolytes. Acc. Chem. Res. 2017, 50, 2653-2660.

(41) Ming, J.; Cao, Z.; Wahyudi, W.; Li, M. L.; Kumar, P.; Wu, Y. Q.; Hwang, J. Y.; Hedhili, M. N.; Cavallo, L.; Sun, Y. K.; Li, L. J. New Insights on Graphite Anode Stability in Rechargeable Batteries: Li Ion Coordination Structures Prevail over Solid Electrolyte Interphases. ACS Energy Lett. 2018, 3, 335-340.

(42) Wahyudi, W.; Cao, Z.; Kumar, P.; Li, M.; Wu, Y.; Hedhili, M. N.; Anthopoulos, T. D.; Cavallo, L.; Li, L.-J.; Ming, J. Phase Inversion Strategy to Flexible Freestanding Electrode: Critical Coupling of Binders and Electrolytes for High Performance Li-S Battery. Adv. Funct. Mater. 2018, 28, 1802244.

(43) Moon, H.; Tatara, R.; Mandai, T.; Ueno, K.; Yoshida, K.; Tachikawa, N.; Yasuda, T.; Dokko, K.; Watanabe, M. Mechanism of $\mathrm{Li}$ Ion Desolvation at the Interface of Graphite Electrode and GlymeLi Salt Solvate Ionic Liquids. J. Phys. Chem. C 2014, 118, 2024620256.

(44) Yamada, Y.; Furukawa, K.; Sodeyama, K.; Kikuchi, K.; Yaegashi, M.; Tateyama, Y.; Yamada, A. Unusual Stability of Acetonitrile-Based Superconcentrated Electrolytes for Fast-Charging Lithium-Ion Batteries. J. Am. Chem. Soc. 2014, 136, 5039-5046.

(45) Wang, J. H.; Yamada, Y.; Sodeyama, K.; Chiang, C. H.; Tateyama, Y.; Yamada, A. Superconcentrated Electrolytes for a HighVoltage Lithium-Ion Battery. Nat. Commun. 2016, 7, 12032.

(46) Lu, D. P.; Tao, J. H.; Yan, P. F.; Henderson, W. A.; Li, Q. Y.; Shao, Y. Y.; Helm, M. L.; Borodin, O.; Graff, G. L.; Polzin, B.; Wang, C. M.; Engelhard, M.; Zhang, J. G.; De Yoreo, J. J.; Liu, J.; Xiao, J. Formation of Reversible Solid Electrolyte Interface on Graphite
Surface from Concentrated Electrolytes. Nano Lett. 2017, 17, 16021609.

(47) Wang, J. H.; Yamada, Y.; Sodeyama, K.; Watanabe, E.; Takada, K.; Tateyama, Y.; Yamada, A. Fire-Extinguishing Organic Electrolytes for Safe Batteries. Nat. Energy 2018, 3, 22-29.

(48) Takeuchi, S.; Miyazaki, K.; Sagane, F.; Fukutsuka, T.; Jeong, S. K.; Abe, T. Electrochemical Properties Of Graphite Electrode in Propylene Carbonate-based Electrolytes Containing Lithium and Calcium Ions. Electrochim. Acta 2011, 56, 10450-10453.

(49) Jeong, S. K.; Inaba, M.; Iriyama, Y.; Abe, T.; Ogumi, Z. Electrochemical Intercalation of Lithium Ion within Graphite from Propylene Carbonate Solutions. Electrochem. Solid-State Lett. 2003, 6, A13-A15.

(50) Wang, J. Z.; Manga, K. K.; Bao, Q. L.; Loh, K. P. High-Yield Synthesis of Few-Layer Graphene Flakes through Electrochemical Expansion of Graphite in Propylene Carbonate Electrolyte. J. Am. Chem. Soc. 2011, 133, 8888-8891.

(51) Tsubouchi, S.; Suzuki, S.; Nishimura, K.; Okumura, T.; Abe, T. Electrochemical Stabilization of Self-Extinguishing Electrolyte Solutions with Trimethyl Phosphate by Adding Potassium Salts. J. Phys. Chem. C 2018, 122, 12657-12664.

(52) Nakagawa, H.; Domi, Y.; Doi, T.; Ochida, M.; Tsubouchi, S.; Yamanaka, T.; Abe, T.; Ogumi, Z. In Situ Raman Study of Graphite Negative-Electrodes in Electrolyte Solution Containing Fluorinated Phosphoric Esters. J. Electrochem. Soc. 2014, 161, A480-A485.

(53) Yim, T.; Han, Y. K. Tris(trimethylsilyl) Phosphite as an Efficient Electrolyte Additive to Improve the Surface Stability of Graphite Anodes. ACS Appl. Mater. Interfaces 2017, 9, 32851-32858.

(54) Lee, Y.; Jung, C. Quantitative and Qualitative Study on the Solid Electrolyte Interface Formed by 2 -(5h) Furanone: A Novel Additive for Propylene Carbonate-Based Lithium-Ion Battery Electrolytes. Electrochim. Acta 2018, 265, 662-669.

(55) Kondo, K.; Sano, M.; Hiwara, A.; Omi, T.; Fujita, M.; Kuwae, A.; Iida, M.; Mogi, K.; Yokoyama, H. Conductivity and Solvation of $\mathrm{Li}^{+}$Ions of $\mathrm{LiPF}_{6}$ in Propylene Carbonate Solutions. J. Phys. Chem. B 2000, 104, 5040-5044.

(56) Ming, J.; Li, M. L.; Kumar, P.; Li, L. J. Multilayer Approach for Advanced Hybrid Lithium Battery. ACS Nano 2016, 10, 6037-6044.

(57) Chang, C. H.; Manthiram, A. Covalently Grafted PolysulfurGraphene Nanocomposites for Ultrahigh Sulfur-Loading Lithium Polysulfur Batteries. ACS Energy Lett. 2018, 3, 72-77.

(58) Shyamsunder, A.; Beichel, W.; Klose, P.; Pang, Q.; Scherer, H.; Hoffmann, A.; Murphy, G. K.; Krossing, I.; Nazar, L. F. Inhibiting Polysulfide Shuttle in Lithium-Sulfur Batteries through Low-IonPairing Salts and a Triflamide Solvent. Angew. Chem., Int. Ed. 2017, 56, 6192-6197.

(59) Zheng, J. M.; Lochala, J. A.; Kwok, A.; Deng, Z. Q. D.; Xiao, J. Research Progress towards Understanding the Unique Interfaces between Concentrated Electrolytes and Electrodes for Energy Storage Applications. Adv. Sci. 2017, 4, 1700032.

(60) Seo, D. M.; Boyle, P. D.; Sommer, R. D.; Daubert, J. S.; Borodin, O.; Henderson, W. A. Solvate Structures and Spectroscopic Characterization of LiTFSI Electrolytes. J. Phys. Chem. B 2014, 118, 13601-13608.

(61) Yamada, Y.; Yaegashi, M.; Abe, T.; Yamada, A. A Superconcentrated Ether Electrolyte for Fast-Charging Li-ion Batteries. Chem. Commun. 2013, 49, 11194-11196.

(62) Moon, H.; Mandai, T.; Tatara, R.; Ueno, K.; Yamazaki, A.; Yoshida, K.; Seki, S.; Dokko, K.; Watanabe, M. Solvent Activity in Electrolyte Solutions Controls Electrochemical Reactions in Li-Ion and Li-Sulfur Batteries. J. Phys. Chem. C 2015, 119, 3957-3970.

(63) Agostini, M.; Scrosati, B.; Hassoun, J. An Advanced LithiumIon Sulfur Battery for High Energy Storage. Adv. Energy Mater. 2015, 5,1500481 .

(64) Li, Z.; Zhang, S.; Terada, S.; Ma, X.; Ikeda, K.; Kamei, Y.; Zhang, C.; Dokko, K.; Watanabe, M. Promising Cell Configuration for Next-Generation Energy Storage: $\mathrm{Li}_{2} \mathrm{~S} / \mathrm{Graphite}$ Battery Enabled by a Solvate Ionic Liquid Electrolyte. ACS Appl. Mater. Interfaces 2016, 8, 16053-16062. 
(65) Bhargav, A.; Wu, M.; Fu, Y. A Graphite-Polysulfide Full Cell with DME-Based Electrolyte. J. Electrochem. Soc. 2016, 163, A1543A1549.

(66) Chen, S.; Yu, Z.; Gordin, M. L.; Yi, R.; Song, J.; Wang, D. A Fluorinated Ether Electrolyte Enabled High Performance Prelithiated Graphite/Sulfur Batteries. ACS Appl. Mater. Interfaces 2017, 9, 69596966.

(67) Zeng, P.; Han, Y.; Duan, X.; Jia, G.; Huang, L.; Chen, Y. A Stable Graphite Electrode in Superconcentrated LiTFSI-DME/DOL Electrolyte and its Application in Lithium-Sulfur Full Battery. Mater. Res. Bull. 2017, 95, 61-70.

(68) Dougherty, D. A. Cation-pi Interactions in Chemistry and Biology: A New View of Benzene, Phe, Tyr, and Trp. Science 1996, $271,163-168$.

(69) Mecozzi, S.; West, A. P.; Dougherty, D. A. Cation-pi Interactions in Aromatics of Biological And Medicinal Interest: Electrostatic Potential Surfaces as a Useful Qualitative Guide. Proc. Natl. Acad. Sci. U. S. A. 1996, 93, 10566-10571.

(70) Cao, Z.; Li, S.; Yan, T. Y. Cation-pi Interactions between a Free-Base Porphyrin and an Ionic Liquid: A Computational Study. ChemPhysChem 2012, 13, 1743-1747.

(71) Bhatt, M. D.; O'Dwyer, C. The Role of Carbonate and Sulfite Additives in Propylene Carbonate-Based Electrolytes on the Formation of SEI Layers at Graphitic Li-Ion Battery Anodes. J. Electrochem. Soc. 2014, 161, X18-X18.

(72) Geysens, P.; Rangasamy, V. S.; Thayumanasundaram, S.; Robeyns, K.; Van Meervelt, L.; Locquet, J. P.; Fransaer, J.; Binnemans, K. Solvation Structure of Sodium Bis(fluorosulfonyl)imide-Glyme Solvate Ionic Liquids and Its Influence on Cycling of Na-MNC Cathodes. J. Phys. Chem. B 2018, 122, 275-289.

(73) Morita, M.; Aoki, S.; Matsuda, Y. AC-Impedance Behavior of Lithium Electrode in Organic Electrolyte-Solutions Containing Additives. Electrochim. Acta 1992, 37, 119-123.

(74) Ming, J.; Cao, Z.; Li, Q.; Wahyudi, W.; Wang, W. X.; Cavallo, L.; Park, K. J.; Sun, Y. K.; Alshareef, H. N. Molecular-Scale Interfacial Model for Predicting Electrode Performance in Rechargeable Batteries. ACS Energy Lett. 2019, 4, 1584-1593.

(75) Zhou, L.; Zhang, J.; Wu, Y.; Wang, W.; Ming, H.; Sun, Q.; Wang, L.; Ming, J.; Alshareef, H. N. Understanding Ostwald Ripening and Surface Charging Effects in Solvothermally-Prepared Metal Oxide-Carbon Anodes for High Performance Rechargeable Batteries. Adv. Energy Mater. 2019, 1902194. 